\title{
Accuracy of anthropometric measurements and weight status perceptions reported by parents of 4 -year-old children
}

\author{
María D Esteban-Vasallo 1,* (1), Ignacio Galán²,3, Maira A Ortiz-Pinto ${ }^{3,4}$, \\ Amelia Astray San Martín ${ }^{5}$, Eva M Cabrero López ${ }^{6}$, María Teresa Morales San José $^{7}$ \\ and Honorato Ortiz-Marrón 8 \\ 'Servicio de Informes de Salud y Estudios, Dirección General de Salud Pública, Consejería de Sanidad, San Martín de \\ Porres 6, Madrid 28035, Spain: ${ }^{2}$ Centro Nacional de Epidemiología, Instituto de Salud Carlos III, Madrid, Spain: \\ ${ }^{3}$ Departamento de Medicina Preventiva y Salud Pública, Universidad Autónoma de Madrid/IdiPAZ, Madrid, Spain: \\ ${ }^{4}$ Departamento de Salud Pública, Universidad Del Norte, Barranquilla, Colombia: ${ }^{5}$ Centro de Salud Soto del Real, \\ Consejería de Sanidad, Madrid, Spain: ${ }^{6}$ Centro de Salud Adelfas, Consejería de Sanidad, Madrid, Spain: ${ }^{7}$ Centro de \\ Salud La Paz, Consejería de Sanidad, Madrid, Spain: ${ }^{8}$ Servicio de Epidemiología, Dirección General de Salud \\ Pública, Consejería de Sanidad, Madrid, Spain
}

Submitted 18 February 2019: Final revision received 15 June 2019: Accepted 3 July 2019: First published online 5 November 2019

\begin{abstract}
Objective: To assess the validity of self-reported height and weight by parents of 4-year-old children and subjective weight perception.

Design: Descriptive cross-sectional study.

Setting: Paediatric population living in the Autonomous Community of Madrid.

Participants: Children born in 2008-2009 examined at 47-59 months of age. Data were collected by paediatricians of the Madrid Primary Care Physicians Sentinel Network. Parents reported weight and height data. Prevalence of weight status categories was calculated using $\mathrm{WHO}$ and International Obesity Task Force (IOTF) reference criteria. Sensitivity, specificity and positive predictive value (PPV) were estimated. The appraisal of their child's weight perception and parental misperception were assessed.

Results: For 2914 children, reported height was underestimated by $-1.38 \mathrm{~cm}$, weight by $-0.25 \mathrm{~kg}$ and BMI was overestimated by $+0.41 \mathrm{~kg} / \mathrm{m}^{2}$ on average. The prevalence of obesity estimated with reported data was 2.7 times higher than that calculated with measured data $(16 \cdot 2 v \cdot 6 \cdot 0 \%)$ according to WHO classification, and 3.6 times higher with IOTF classification. Sensitivity to identify obesity was $70.5 \%$, specificity was $87.3 \%$ and PPV was $26 \cdot 2 \%$ (WHO classification). Half of the parents of pre-schoolers with obesity failed to identify their child's weight status. Parental misperception among children classified as having overweight or obesity reached 93.0 and $58.8 \%$, respectively.

Conclusions: Parents underestimated children's height and weight, leading to an overestimation of the prevalence of obesity. Small inaccuracies in reported measures have an important effect for the estimation of population prevalences. Parents' report of child weight status is unreliable. Parental awareness and acknowledgement of child weight status should be improved.
\end{abstract}

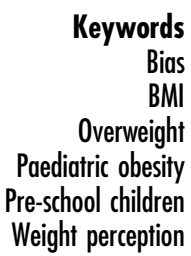

Excess of weight at a young age is an important risk factor for overweight/obesity in adolescence and adult age ${ }^{(1,2)}$ and increases the likelihood of early morbidity and mortality ${ }^{(3,4)}$. The prevalence of overweight and obesity in children and adolescents has become a public health problem in developed countries. Their estimated prevalence is about $20 \%$ in the WHO European Region ${ }^{(5)}$.
Routine surveillance of overweight and obesity is essential to assess population changes and trends, and to evaluate the success of policies aimed to reduce the excess of weight in childhood and eventually bring to a halt to the ongoing obesity epidemic. Reliable data are crucial to estimate accurate prevalences of overweight and obesity and to allow comparisons. Measured weight and height 
would be the gold standard for surveillance, as for example in the Childhood Obesity Surveillance Initiative (COSI) established in 2006 by the WHO Regional Office for Europe to monitor changes in overweight in children between 6 and 9 years of age ${ }^{(6)}$. However, a recent review of studies reporting on overweight and obesity prevalence in children aged $0-5$ years in the WHO European Region member states showed the need for an increased range of coverage and quality of data in surveillance on overweight and obesity in this age group ${ }^{(7)}$.

However, measurements are expensive and they do not always have the desired availability or frequency. Parent-reported data can be an affordable alternative, and they are commonly used in population surveys, but published studies have shown poor accuracy of these measures. This effect seems to be even greater among the youngest. The obesity prevalence based on the parental-reported weight and height obtained by two national health surveys in the USA in the last decade was overestimated by a factor of 5 for children aged 2-3 years and by a factor of 3 for children aged 3-7 years ${ }^{(8)}$. Accordingly, the use of parental-reported height and weight and calculated BMI was discarded for children younger than 10 years $^{(9)}$. Nevertheless, the Spanish National Health Survey (SNHS) keeps using reported measures and recently published the 2017 results, with an estimated prevalence of $12.0 \%$ for overweight and $19.9 \%$ for obesity in children $2-4$ years of age ${ }^{(10)}$.

Parents' ability to identify their child's overweight status has been also questioned in different studies. Pooled results from a systematic review found that $62.4 \%$ of children with overweight were incorrectly perceived as having normal weight by their parents, with a higher misperception among parents with children aged 2-6 years ${ }^{(11)}$. Potential for success in overweight and obesity prevention may lie with family-based interventions. Parental misperceptions of overweight and associated health risks constitute unfavourable conditions for preventive actions ${ }^{(12)}$.

There is little evidence about the potential deviation of anthropometric data provided by parents of pre-schoolers in Spain and the bias that could produce in the prevalence of overweight and obesity estimated with them. These population prevalences are usually calculated with reported measures collected by surveys, and without objective measures to compare or any validation. Their inaccuracy could lead to biased results that even could affect some weight status categories more than others. In regard to parents' weight perception, up to $60.8 \%$ failed to recognize excess weight in their children according to the 2006-2007 SNHS (using reported measures as reference, since objective height and weight are not collected in this survey), rising to $71.4 \%$ in the $2011-2012$ $\mathrm{SNHS}^{(13)}$. It would be necessary to compare parents' weight perception with the objective measures of the children to assess the accuracy of that appraisal and the extent of weight status misperception.
The objective of the present study was to assess the validity of height, weight and subjective weight perception reported by parents of 4-year-old children and the accuracy of overweight/obesity classification based on that information.

\section{Methods}

\section{Design and study population}

This is a descriptive cross-sectional study. The data were drawn from the Longitudinal Childhood Obesity Study (ELOIN), a population-based children's cohort in the Autonomous Community of Madrid, Spain. That study started in 2012 and aims to describe the prevalence and variations in childhood overweight and obesity, ascertaining their association with sociodemographic and lifestyle factors, as well as their impact on health. The design and characteristics of ELOIN have already been described elsewhere ${ }^{(14)}$. Inclusion criteria were being born between January 2008 and November 2009 and being registered in the health-care database with one of the thirty-one paediatricians who were part of the Madrid Primary Care Physicians Sentinel Surveillance Network ${ }^{(15)}$. To ensure proportional distribution by socio-economic level of the assisted population, fourteen strata are defined according to sociodemographic variables that characterize the health areas (first-stage units). This guarantees the representativeness at regional level of the population assisted by the network. Participation in the study was offered via letter to parents of children who reached the age of 4 years between 2012 and 2013. Data of children examined at 47-59 months of age were included in the analysis.

\section{Measures}

\section{Height and weight reported by parents}

Parents of children who attended the paediatric revision consultation scheduled for the age of 4 years in the primary-care health centre were asked to report the current height and weight of their child (see online supplementary material, Supplemental Table S1).

\section{Height and weight measured by professionals}

A physical examination was performed on the children. Paediatricians were previously trained to obtain standardized measurements of weight and height. Weight was measured using a digital scale and height was measured using a telescopic stadiometer (SECA model 220, precision $0 \cdot 1 \mathrm{~kg}$ and $1 \mathrm{~mm}$, respectively). Two measurements of height (without shoes) and two of weight (in underwear) were obtained and registered in the electronic clinical record (recorded in centimetres and in kilograms with one decimal, respectively). The mean of the two measurements was used for the analyses. BMI, both for reported and for objective measures, was calculated with the formula: $\mathrm{kg} / \mathrm{m}^{2}$. 
Parents'perception of child's weight status obtained by telephonic survey

In the following weeks, a telephonic questionnaire was applied to those parents who agreed to participate in the ELOIN cohort, gathering information on sociodemographic characteristics, dietary patterns and lifestyles. Parents' visual perception of the child's weight status was assessed with the question 'Compared to children of the same age, how do you think is your child?', with a five-option answer: 'I think he/she is fat', 'I think he/she has excessive weight', 'I think he/she has a normal weight', 'I think he/she is a little thin' and 'I think he/she is thin'.

\section{Data analyses}

\section{Cleaning of reported data}

Records with biologically implausible values for reported height and weight and calculated BMI were excluded, according to the WHO exclusion criteria ( $Z$-score for gender-specific weight-for-height $<-4.0$ or $>+5 \cdot 0$, heightfor-age $<-5.0$ and $>+3.0$, and weight-for-age $<-5.0$ and $>+5 \cdot 0)$. A total of four weights and thirty-one heights were discarded as biologically implausible values ( 0.1 and $1.0 \%$, respectively). Of the $2931 \mathrm{BMI}$ calculated with the remaining reported measures, seventeen were also discarded as biologically implausible values (0.6\%).

\section{Comparisons between reported and measured data}

The mean absolute and relative differences between reported and measured height, weight and BMI were calculated. To assess agreement between reported and measured height, weight and BMI, intraclass correlation coefficients were estimated.

\section{Categorization of weight status based on reported and} measured data

The WHO growth charts for 2006 and the cut-off points of the International Obesity Task Force (IOTF) for 2000 were used to assign BMI categories. Based on the reported and measured children's weight and height, the weight categories were calculated by sex. Using the WHO criteria $^{(16)}$, BMI $Z$-scores were calculated according to child growth standards for those aged 60 months or younger. Thereby, participants were classified into four categories by BMI $Z$-score: obesity $(>+2)$; overweight $(>+1$ and $\leq+2)$; normal weight $(\geq-2$ and $\leq+1)$; and low weight $(<-2)$. The extended IOTF BMI cut-offs proposed by Cole et al. ${ }^{(17,18)}$ to classify children aged from 2 to 18 years were used, with the interpolated biannual values.

\section{Comparisons of weight status categories based on} reported and measured data

We compared prevalence of weight status (obesity/ overweight/normal weight/low weight) based on measured and reported data. The kappa test with quadratic weighting was used to determine the agreement between the weight status assigned through reported $v$. measured anthropometric data. The degree of misclassification that resulted from using reported measures was assessed. Sensitivity (children with overweight or obesity according to reported and measured data/children with overweight or obesity according to measured data), specificity (children without overweight or obesity according to reported and measured data/children without overweight or obesity according to measured data) and positive predictive value (PPV; children with overweight or obesity according to reported and measured data/children with overweight or obesity according to reported data) were calculated.

\section{Parental misperception}

For the assessment of parents' visual perception of their child's weight status, the parental misperception was defined as follows: children with overweight or obesity according to their measured height and weight but described by their parents as 'normal weight', 'a little thin' or 'thin'. Children described as 'fat' or 'having excessive weight' were excluded from the definition of parental misperception.

The data were analysed using the statistical software package IBM SPSS Statistics version 22.

\section{Results}

In total, 2914 of the 4571 children screened at age 4 years had valid height and weight both reported and measured, representing a response rate of $63.7 \%$.

\section{Comparisons between reported and measured data}

On average, child height was underestimated by $1.38 \mathrm{~cm}$ and weight by $0.25 \mathrm{~kg}$ (Table 1). Overall, BMI was $0.41 \mathrm{~kg} / \mathrm{m}^{2}$ higher when based on reported $v$. measured height and weight. The bias in BMI was larger for boys, due to a greater deviation of the reported height: the mean absolute differences between reported and measured height were $-1.56 \mathrm{~cm}$ for boys $v .-1.19 \mathrm{~cm}$ for girls, and the mean relative differences were -1.50 and $-1.16 \%$, respectively. For weight the absolute differences were $-0.23 \mathrm{~kg}$ for boys and $-0.27 \mathrm{~kg}$ for girls (relative differences of -1.34 and $-1.58 \%$, respectively), and for BMI the absolute differences were $+0.46 \mathrm{~kg} / \mathrm{m}^{2}$ for boys and $+0.34 \mathrm{~kg} / \mathrm{m}^{2}$ for girls (relative differences of +2.92 and $+2 \cdot 18 \%$, respectively). Nevertheless, these differences by sex were not statistically significant. There was no difference between BMI $Z$-scores estimated with reported and measured data for girls, meanwhile for boys the BMI $Z$-score estimated with reported data was significantly higher.

When children's weight status was categorized according to the WHO or IOTF classification, a significant underrating of height was detected in all groups except 
Table 1 Mean parent-reported and measured anthropometric data in 4-year-old children, by sex. Autonomous Community of Madrid, Spain, $2012(n 2914)$

\begin{tabular}{|c|c|c|c|c|c|c|c|c|}
\hline & \multicolumn{2}{|c|}{ Parent-reported } & \multicolumn{2}{|c|}{ Measured } & \multicolumn{2}{|c|}{$\begin{array}{l}\text { Absolute difference } \\
\text { (reported minus } \\
\text { measured) }\end{array}$} & \multicolumn{2}{|c|}{$\begin{array}{l}\text { Relative difference } \\
\text { (reported minus } \\
\text { measured) }\end{array}$} \\
\hline & Mean & $95 \% \mathrm{Cl}$ & Mean & $95 \% \mathrm{Cl}$ & Mean & $95 \% \mathrm{Cl}$ & $\%$ & $95 \% \mathrm{Cl}$ \\
\hline \multicolumn{9}{|l|}{ Mean height $(\mathrm{cm})$} \\
\hline Total $(n 2914)$ & $102 \cdot 15$ & $101 \cdot 87,102 \cdot 43$ & 103.53 & $103.37,103.69$ & -1.38 & $-1 \cdot 63,-1.13$ & -1.33 & $-1.58,-1.09$ \\
\hline Boys (n1486) & $102 \cdot 47$ & $102 \cdot 09,102 \cdot 84$ & 104.02 & $103.80,104.25$ & -1.56 & $-1.90,-1.22$ & -1.50 & $-1.83,-1.17$ \\
\hline Girls ( $n$ 1428) & $101 \cdot 82$ & $101 \cdot 41,102 \cdot 23$ & 103.01 & $102 \cdot 79,103 \cdot 24$ & -1.19 & $-1.56,-0.82$ & $-1 \cdot 16$ & $-1.52,-0.80$ \\
\hline \multicolumn{9}{|l|}{ Mean weight $(\mathrm{kg})$} \\
\hline Total (n2914) & $16 \cdot 79$ & $16 \cdot 69,16 \cdot 90$ & $17 \cdot 04$ & $16 \cdot 95,17 \cdot 13$ & -0.25 & $-0.32,-0.18$ & -1.46 & $-1.85,-1.06$ \\
\hline Boys ( $n 1486)$ & 17.02 & $16 \cdot 86,17 \cdot 17$ & $17 \cdot 25$ & $17 \cdot 12,17 \cdot 37$ & -0.23 & $-0.33,-0.13$ & -1.34 & $-1.89,-0.78$ \\
\hline Girls ( $n$ 1428) & $16 \cdot 56$ & $16 \cdot 41,16 \cdot 72$ & $16 \cdot 83$ & $16 \cdot 70,16 \cdot 96$ & -0.27 & $-0.36,-0.17$ & -1.58 & $-2 \cdot 16,-1.01$ \\
\hline \multicolumn{9}{|l|}{ Mean BMI $\left(\mathrm{kg} / \mathrm{m}^{2}\right)$} \\
\hline Total $(n 2914)$ & $16 \cdot 26$ & $16 \cdot 13,16 \cdot 38$ & $15 \cdot 85$ & $15 \cdot 79,15 \cdot 91$ & 0.41 & $0.29,0.52$ & 2.56 & $1.86,3.26$ \\
\hline Boys ( $n 1486)$ & $16 \cdot 36$ & $16.18,16.53$ & $15 \cdot 89$ & $15.81,15.97$ & 0.46 & $0.31,0.61$ & 2.92 & $1.97,3.87$ \\
\hline Girls ( $n 1428)$ & $16 \cdot 15$ & $15 \cdot 97,16 \cdot 34$ & $15 \cdot 81$ & $15 \cdot 72,15 \cdot 90$ & 0.34 & $0.18,0.51$ & $2 \cdot 18$ & $1 \cdot 14,3 \cdot 21$ \\
\hline \multicolumn{9}{|c|}{ Mean BMI Z-score* } \\
\hline Total (n2914) & 0.39 & $0.31,0.47$ & 0.33 & $0.29,0.37$ & 0.06 & $-0.01,0.12$ & - & - \\
\hline Boys ( $n 1486)$ & 0.49 & $0.37,0.60$ & 0.37 & $0.31,0.42$ & 0.12 & $0.02,0.12$ & - & - \\
\hline Girls (n 1428) & 0.29 & $0.19,0.39$ & 0.29 & $0.24,0.35$ & 0.00 & $-0.10,0.09$ & - & - \\
\hline
\end{tabular}

Statistically significant differences are indicated in bold.

${ }^{\star}$ No relative differences could be calculated due to measured BMI $Z$-score values equal to zero.

those with low weight according to the WHO classification (see online supplementary material, Supplemental Table S2). This deviation was proportionately greater among children with obesity. Weight was significantly underestimated in children with overweight and normal weight, and among girls with obesity, according to the IOTF classification. A significant overestimation of BMI was appreciated in all categories except for low weight when the WHO classification was used, and in children with normal weight when the IOTF classification was used. By weight category, there were no statistically significant differences in the inaccuracy of height, weight or BMI, except in the height of girls classified as 'low weight' according to the IOTF classification, when compared with girls classified as 'normal weight'.

Findings from intraclass correlation coefficients showed moderate correlation between reported and measured height: $0.543 \quad(P<0.01), 0.538$ for boys $(P<0.01)$ and 0.542 for girls $(P<0.01)$. The correlation between reported and measured weight was the highest, 0.865 $(P<0.01)$, with good correlation both for boys and girls ( 0.860 and 0.868 , respectively). The intraclass correlation coefficient between BMI calculated with reported and objective measures was $0.512(P<0.01 ; 0.514$ for boys and 0.509 for girls).

\section{Comparisons of weight status categories based on reported and measured data}

The prevalence of obesity estimated with reported height and weight was $2 \cdot 7$ times higher than that calculated with measured height and weight $(16 \cdot 2$ (95 \% CI 14.9, 17.6) \% v .
$6 \cdot 0(95 \%$ CI $5 \cdot 2,6 \cdot 9) \%)$ according to the WHO classification, and 3.6 times higher $(12 \cdot 1$ (95\% CI 11.0, 13.4) \% v.3.3 (95\% CI $2.7,4.0) \%$ ) when using the IOTF classification (Table 2). The overestimation of the prevalence in the extreme categories (obesity and low weight) was slightly higher among boys. The agreement between the assigned weight status through reported $v$. measured anthropometric data was moderate-low, with a weighted $\kappa$ coefficient of 0.405 (95\% CI $0.371,0.439$ ) when using the WHO classification and 0.350 (95\% CI $0.313,0.387)$ with the IOTF classification.

The sensitivity of using reported height and weight to identify obesity according to the WHO classification was 70.5 (95\% CI $63.1,77.1) \%$, specificity was 87.3 (95\% CI 85.9, 88.5) \% and PPV was 26.2 (95\% CI 22.3, $30.4) \%$ (Table 3). Thus, reported measures misclassified $29.5 \%$ of children with obesity $(32.3 \%$ in boys and $26.5 \%$ in girls). When using the IOTF classification, the effect of misclassification with reported measures was similar. By sex, the only statistically significant difference was detected for PPV (39.3\% in girls $v .28 .3 \%$ in boys) with the IOTF classification and grouping overweight and obesity. The weight category assigned using reported or objective measures was the same for $60.0 \%$ of the children when the WHO classification was used and $62.9 \%$ with the IOTF classification (Fig. 1). Using reported measures $27.5 \%$ of children with overweight were classified as with obesity $(30.1 \%$ with the IOTF classification), while in $39.6 \%$ ( $40.8 \%$ with the IOTF classification) the category was underestimated. Among those children with normal weight, $22.8 \%$ were erroneously assigned to excess weight 
Table 2 Prevalence of weight status estimated using parent-reported or measured height and weight, and prevalence ratio (PR), in 4-year-old children, by sex and weight status classification. Autonomous Community of Madrid, Spain, 2012 ( $n 2914$ )

\begin{tabular}{|c|c|c|c|c|c|c|c|c|c|c|}
\hline & \multicolumn{5}{|c|}{ WHO classification } & \multicolumn{5}{|c|}{ IOTF classification } \\
\hline & \multicolumn{2}{|c|}{ Parent-reported } & \multicolumn{2}{|c|}{ Measured } & \multirow[b]{2}{*}{ PR } & \multicolumn{2}{|c|}{ Parent-reported } & \multicolumn{2}{|c|}{ Measured } & \multirow[b]{2}{*}{ PR } \\
\hline & $\%$ & $95 \% \mathrm{Cl}$ & $\%$ & $95 \% \mathrm{Cl}$ & & $\%$ & $95 \% \mathrm{Cl}$ & $\%$ & $95 \% \mathrm{Cl}$ & \\
\hline \multicolumn{11}{|l|}{ Total } \\
\hline Obesity & $16 \cdot 2$ & $14 \cdot 9,17 \cdot 6$ & $6 \cdot 0$ & $5 \cdot 2,6 \cdot 9$ & $2 \cdot 7$ & $12 \cdot 1$ & $11 \cdot 0,13 \cdot 4$ & 3.3 & $2 \cdot 7,4 \cdot 0$ & 3.6 \\
\hline Overweight & $16 \cdot 8$ & $15 \cdot 5,18 \cdot 2$ & $17 \cdot 3$ & $16 \cdot 0,18 \cdot 7$ & 1.0 & $12 \cdot 7$ & $11 \cdot 6,14 \cdot 0$ & $9 \cdot 3$ & $8 \cdot 3,10 \cdot 4$ & 1.4 \\
\hline Normal weight & 56.9 & $55 \cdot 1,58 \cdot 7$ & 75.7 & $74 \cdot 1,77 \cdot 2$ & 0.8 & $61 \cdot 3$ & $59 \cdot 6,63 \cdot 1$ & 84.0 & $82 \cdot 7,85 \cdot 3$ & 0.7 \\
\hline Low weight & $10 \cdot 1$ & $9 \cdot 1,11 \cdot 3$ & 0.9 & $0.6,1.3$ & $10 \cdot 9$ & $13 \cdot 8$ & $12 \cdot 6,15 \cdot 1$ & 3.3 & $2 \cdot 7,4 \cdot 0$ & 4.2 \\
\hline \multicolumn{11}{|l|}{ Boys } \\
\hline Obesity & $18 \cdot 0$ & $16 \cdot 1,20 \cdot 0$ & $6 \cdot 2$ & $5 \cdot 1,7 \cdot 6$ & $2 \cdot 9$ & $12 \cdot 4$ & $10 \cdot 8,14 \cdot 2$ & $2 \cdot 7$ & $1.9,3 \cdot 6$ & $4 \cdot 6$ \\
\hline Overweight & $16 \cdot 6$ & $14.7,18.5$ & $17 \cdot 7$ & $15 \cdot 8,19 \cdot 7$ & 0.9 & $12 \cdot 0$ & $10 \cdot 4,13 \cdot 8$ & $7 \cdot 9$ & $6 \cdot 6,9 \cdot 3$ & 1.5 \\
\hline Normal weight & $55 \cdot 2$ & $52 \cdot 6,57 \cdot 7$ & $75 \cdot 3$ & $73 \cdot 1,77 \cdot 4$ & 0.7 & $62 \cdot 8$ & $60 \cdot 4,65 \cdot 3$ & $86 \cdot 7$ & $84 \cdot 9,88 \cdot 3$ & 0.7 \\
\hline Low weight & $10 \cdot 3$ & $8.8,11.9$ & 0.7 & $0.4,1.3$ & 13.9 & $12 \cdot 6$ & $11 \cdot 0,14.4$ & $2 \cdot 7$ & $2 \cdot 0,3 \cdot 7$ & 4.6 \\
\hline \multicolumn{11}{|l|}{ Girls } \\
\hline Obesity & 14.4 & $12 \cdot 7,16 \cdot 3$ & $5 \cdot 8$ & $4 \cdot 7,7 \cdot 1$ & 2.5 & 11.8 & $10 \cdot 2,13 \cdot 6$ & $4 \cdot 0$ & $3 \cdot 1,5 \cdot 1$ & 3.0 \\
\hline Overweight & $17 \cdot 0$ & $15 \cdot 1,19 \cdot 0$ & $16 \cdot 9$ & $15 \cdot 1,19 \cdot 0$ & 1.0 & 13.4 & $11 \cdot 7,15 \cdot 3$ & $10 \cdot 8$ & $9.3,12.5$ & 1.2 \\
\hline Normal weight & 58.6 & $56 \cdot 0,61 \cdot 1$ & $76 \cdot 1$ & $73 \cdot 9,78 \cdot 3$ & 0.8 & 59.7 & $57 \cdot 2,62 \cdot 3$ & 81.3 & $79 \cdot 2,83 \cdot 3$ & $0 . \overline{7}$ \\
\hline Low weight & 9.9 & $8.5,11.6$ & 1.1 & $0.7,1.8$ & 8.9 & $15 \cdot 0$ & $13 \cdot 2,16 \cdot 9$ & 3.8 & $2.9,4.9$ & 3.9 \\
\hline
\end{tabular}

IOTF, International Obesity Task Force.

Table 3 Sensitivity, specificity and positive predictive value (PPV) of obesity and overweight using parent-reported measures in 4-year-old children, by sex and weight status classification. Autonomous Community of Madrid, Spain, $2012(n 2914)$

\begin{tabular}{|c|c|c|c|c|c|c|}
\hline & \multicolumn{2}{|c|}{ Sensitivity } & \multicolumn{2}{|c|}{ Specificity } & \multicolumn{2}{|c|}{ PPV } \\
\hline & $\%$ & $95 \% \mathrm{Cl}$ & $\%$ & $95 \% \mathrm{Cl}$ & $\%$ & $95 \% \mathrm{Cl}$ \\
\hline \multicolumn{7}{|l|}{ Obesity } \\
\hline \multicolumn{7}{|c|}{ WHO classification } \\
\hline Total & 70.5 & $63 \cdot 1,77 \cdot 1$ & $87 \cdot 3$ & $85 \cdot 9,88.5$ & $26 \cdot 2$ & $22 \cdot 3,30 \cdot 4$ \\
\hline Boys & $67 \cdot 7$ & $57 \cdot 2,77 \cdot 1$ & 85.4 & $83 \cdot 4,87 \cdot 2$ & $23 \cdot 6$ & $18 \cdot 6,29 \cdot 1$ \\
\hline Girls & 73.5 & $62 \cdot 7,82 \cdot 6$ & $89 \cdot 2$ & $87 \cdot 4,90 \cdot 8$ & $29 \cdot 6$ & $23 \cdot 5,36 \cdot 3$ \\
\hline \multicolumn{7}{|c|}{ IOTF classification } \\
\hline Total & 68.0 & $57 \cdot 8,77 \cdot 1$ & $89 \cdot 8$ & $88 \cdot 6,90 \cdot 9$ & $18 \cdot 6$ & $14 \cdot 7,23 \cdot 1$ \\
\hline Boys & $70 \cdot 0$ & $53 \cdot 5,83 \cdot 4$ & $89 \cdot 1$ & $87 \cdot 4,90 \cdot 7$ & $15 \cdot 1$ & $10 \cdot 3,21 \cdot 1$ \\
\hline Girls & $66 \cdot 7$ & $52 \cdot 9,78 \cdot 6$ & $90 \cdot 4$ & $88.8,91 \cdot 9$ & $22 \cdot 5$ & $16 \cdot 4,29 \cdot 5$ \\
\hline \multicolumn{7}{|c|}{ Overweight } \\
\hline \multicolumn{7}{|c|}{ WHO classification } \\
\hline Total & $32 \cdot 9$ & $28 \cdot 8,37 \cdot 2$ & $86 \cdot 6$ & $85 \cdot 2,87 \cdot 9$ & 33.9 & $29.8,38 \cdot 3$ \\
\hline Boys & 31.9 & $26 \cdot 3,37 \cdot 9$ & $86 \cdot 8$ & $84 \cdot 7,88 \cdot 6$ & $34 \cdot 1$ & $28 \cdot 2,40 \cdot 4$ \\
\hline Girls & 33.9 & $27 \cdot 9,40 \cdot 2$ & $86 \cdot 4$ & $84 \cdot 3,88 \cdot 3$ & 33.7 & $27 \cdot 8,40 \cdot 1$ \\
\hline \multicolumn{7}{|c|}{ IOTF classification } \\
\hline Total & $29 \cdot 0$ & $23 \cdot 7,34 \cdot 8$ & $88 \cdot 9$ & $87 \cdot 7,90 \cdot 1$ & $21 \cdot 3$ & $17 \cdot 2,25 \cdot 8$ \\
\hline Boys & $28 \cdot 2$ & $20 \cdot 3,37 \cdot 3$ & $89 \cdot 3$ & $87 \cdot 6,90 \cdot 9$ & $18 \cdot 4$ & $13 \cdot 0,24 \cdot 9$ \\
\hline Girls & 29.7 & $22 \cdot 6,37.5$ & 88.5 & $86 \cdot 6,90 \cdot 2$ & $24 \cdot 0$ & $18 \cdot 1,30 \cdot 6$ \\
\hline \multicolumn{7}{|c|}{ Overweight + obesity } \\
\hline \multicolumn{7}{|c|}{ WHO classification } \\
\hline Total & $67 \cdot 0$ & $63 \cdot 3,70 \cdot 4$ & $77 \cdot 3$ & $75 \cdot 6,79 \cdot 0$ & 47.4 & $44 \cdot 3,50 \cdot 6$ \\
\hline Boys & $66 \cdot 9$ & $61 \cdot 8,71 \cdot 5$ & $75 \cdot 7$ & $73 \cdot 1,78 \cdot 1$ & $46 \cdot 4$ & $42 \cdot 1,50 \cdot 7$ \\
\hline Girls & $67 \cdot 1$ & $61 \cdot 8,72 \cdot 0$ & 79.1 & $76 \cdot 6,81 \cdot 4$ & 48.6 & $44 \cdot 0,53 \cdot 2$ \\
\hline \multicolumn{7}{|c|}{ IOTF classification } \\
\hline Total & $66 \cdot 4$ & $61 \cdot 4,71 \cdot 0$ & $81 \cdot 1$ & $79 \cdot 6,82 \cdot 6$ & 33.8 & $30 \cdot 4,37 \cdot 3$ \\
\hline Boys & $65 \cdot 6$ & $57 \cdot 9,72 \cdot 6$ & $80 \cdot 4$ & $78 \cdot 1,82 \cdot 4$ & $28 \cdot 3$ & $23 \cdot 9,33 \cdot 1$ \\
\hline Girls & $67 \cdot 0$ & $60 \cdot 4,73 \cdot 0$ & $82 \cdot 0$ & $79 \cdot 7,84 \cdot 0$ & $39 \cdot 3$ & $34.4,44.5$ \\
\hline
\end{tabular}

IOTF, International Obesity Task Force.

(19.4\% with the IOTF classification). Of underweight children, $55.6 \%$ were correctly classified using the reported measures $(53.1 \%$ with the IOTF classification). Findings from the weighted $\kappa$ test showed moderate agreement between the weight status category assigned with reported v. measured data (0.4048 (95\% CI 0.3708, 0.4387), $P<0.01$ using the WHO classification; 0.3498 (95\% CI 0.3129 , $0.3867), P<0.01$ using the IOTF classification). 

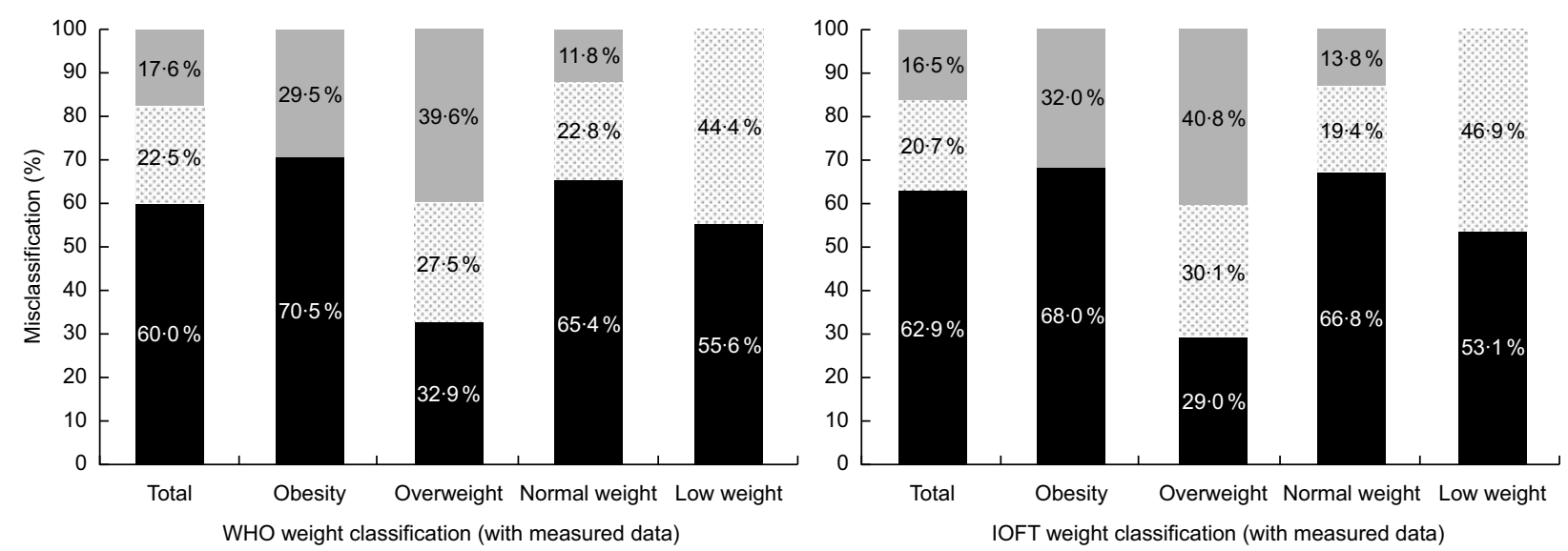

Fig. 1 Proportion of weight status misclassification (घ, same weight status category; ${ }^{2}$, higher weight status category; $\square$, lower weight status category) with parent-reported data in children aged 4 years when compared with weight status calculated using measured data (WHO and International Obesity Task Force (IOTF) classifications). Autonomous Community of Madrid, Spain, 2012 (n2529)

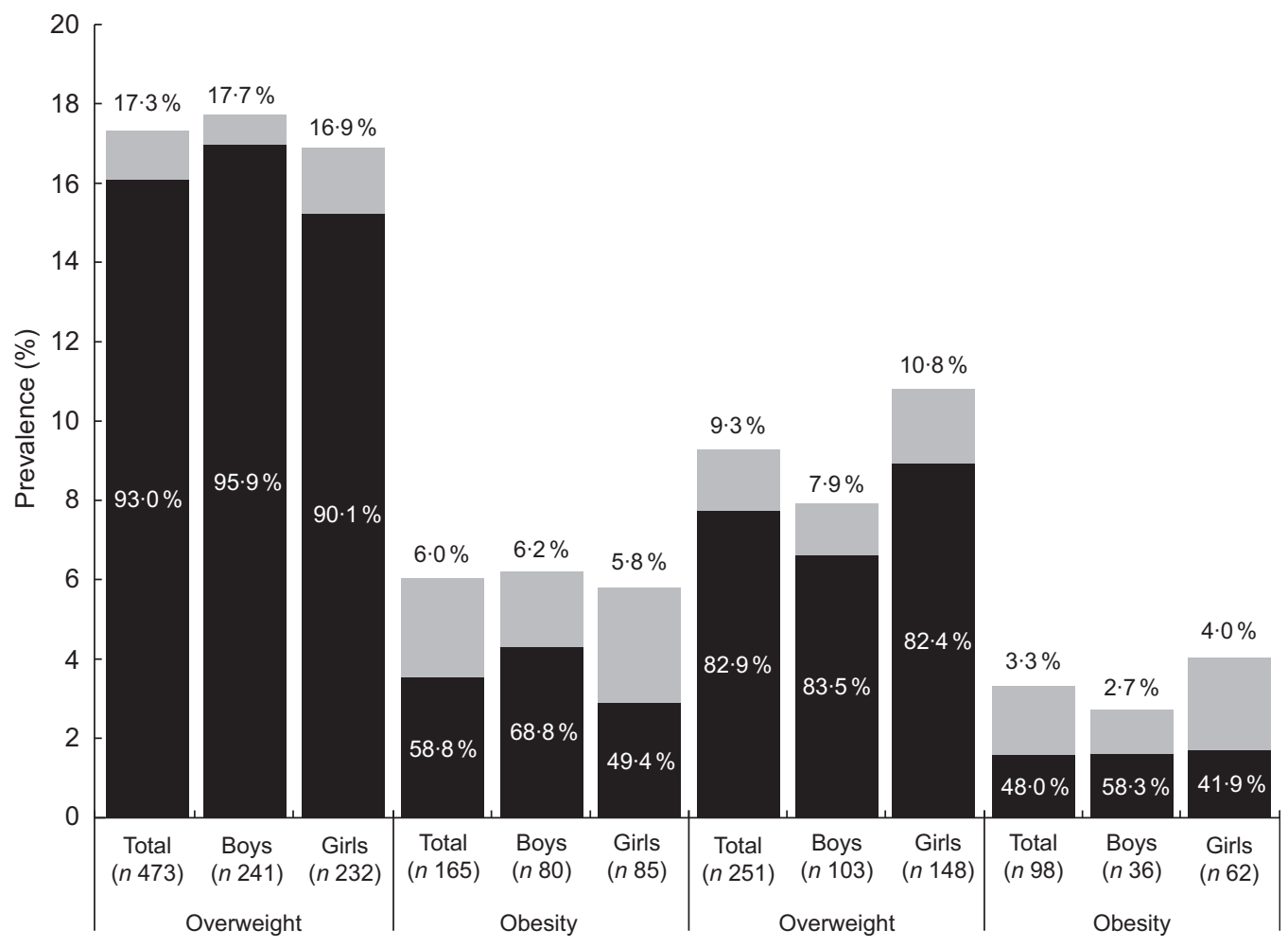

WHO weight classification (with measured data) IOTF weight classification (with measured data)

Fig. 2 Prevalence of overweight and obesity calculated with measured data in children aged 4 years (WHO and International Obesity Task Force (IOTF) classifications; values above bars), and proportion of parental misperception* (泣; values within bars), in total and by sex. Autonomous Community of Madrid, Spain, 2012 (n2529). *Parental misperception: child described by parents as having 'normal weight', 'a little thin' or 'thin' and classified in the category 'overweight' or 'obesity' according to measured data

\section{Parental misperception}

The parental misperception among children classified as being with overweight or obesity according to the WHO classification reached 93.0 and $58.8 \%$, respectively (Fig. 2). When the IOTF classification was used, parental misperception was lower, affecting $82.9 \%$ of parents of children with overweight and $48.0 \%$ of parents of children with obesity. The parental misperception for boys with obesity was higher than for girls. 


\section{Discussion}

The present study provides a global perspective on information sources of the weight status of pre-schoolers, by analysing data from objective measures, parent-reported measures and also parents' subjective appraisal of their child's weight status. The availability of standardized measures obtained by trained professionals provides a gold standard to evaluate the internal validity of parent-reported data and to assess the bias these data could generate. Parent-reported height and weight were found to be subject to errors that affect the ability to classify the weight status into the correct category and to identify overweight and obesity accurately among children 4 years of age. Inaccuracies apparently small in the reported measures of height and weight have an important effect for the estimation of population prevalences. Only $70 \%$ of children with obesity were correctly classified using parent-reported data, meanwhile over $20 \%$ of children with normal weight were erroneously assigned to excess weight. Therefore, the use of parent-reported measures could overestimate the real prevalence of obesity at this age by up to 2.7 times when using the WHO classification (3.6 times with the IOTF classification). The subjective perception about the child's overweight and obesity was inadequate in a high proportion of parents.

\section{Reported height and weight}

Although in the published literature the deviation of the reported height and weight of pre-schoolers varies widely, previous studies in our country found, similarly to our data, an underestimation of both reported measures (up to $10 \%$ in the case of weight) in children under 14 years of age ${ }^{(19,20)}$. This underestimation seemed to be even more marked in children under 4 years of age ${ }^{(19)}$. The deviation of both reported height and weight observed in our sample was also found in international studies ${ }^{(21-23)}$. Apparently, parents are more likely to underestimate height than weight, as described among parents of children aged 2-8 years in the analysis of a sub-sample of the 2006 and 2008 waves of the National Longitudinal Survey of Youth 1979 Cohort (NLSY79-Child) in the USA ${ }^{(23)}$. This could be because parents would be more likely to track children's weight than height, at these ages. The fact that in children most drugs are dosed according to body weight could at least partially justify a better retention and/or update of this measure.

As in other studies, no significant differences by sex in height or weight misreporting were found for young children $^{(23)}$, despite a larger mean height error was found in boys. This effect has been described previously in boys between 2 and 17 years of age ${ }^{(24)}$, and also a Canadian study found that height errors varied by the child's sex, with slight overestimation in boys and underestimation in girls $^{(25)}$. However, when measures reported for children aged 6-11 years were analysed, the bias found in height did not differ significantly by the child's sex or age group, but the bias in weight was significantly higher for girls than boys $^{(22)}$.

\section{Prevalences}

Prevalence of overweight/obesity among pre-school children based on parent-reported data of height and weight was significantly higher than prevalence based on direct measurements, as other studies have found $^{(8,22,24-29)}$. The bias in height was not offset by the bias in weight, and as a result BMI values based on reported measures were overestimated, as in other studies $^{(19-21,23,24)}$. A simulation method developed to assess bias from using parent-reported data on heights and weights in two nationally representative US surveys estimated that the source of one-half to two-thirds of the overestimation in obesity prevalence in children aged 2-5 years was due to height reporting error manifest in the first height percentile ${ }^{(30)}$. The sensitivity and specificity of using reported height and weight to identify obesity status were slightly higher than the 55 and $79 \%$, respectively, described by O'Connor and Gugenheim among children between 2 and 5 years of age ${ }^{(24)}$, but lower than the 84.4 and $79.3 \%$ described by Gordon and Mellor for the obesity classification (BMI-for-age percentile $\geq 95$ th) in children 3-5 years old ${ }^{(21)}$. Therefore, the use of parent-reported height and weight does not guarantee the correct weight status classification for 4-year-old children and, at population level, leads to the overestimation of obesity and overweight prevalences, as a recent meta-analyses of similar studies showed ${ }^{(31)}$. These circumstances discourage the use of reported measures for the surveillance and monitoring of pre-schoolers' nutritional status, and highlight the need for objective measures, especially in this less studied age group, to have accurate data at either individual level or population level, and to facilitate comparisons with other populations ${ }^{(32)}$.

\section{Parental misperception}

In regard to parental misperception of the children's weight status, the proportion of parents of children with overweight or obesity who perceived them as having a normal or low weight was high, similarly to other studies $^{(11,13,21,33-38)}$. In Spain, a study assessing the wrong perception of excess weight among parents of children between 5 and 9 years old using data from the 2011-2012 SNHS found that $79.7 \%$ of parents of children with overweight and $70.3 \%$ of parents of children with obesity (according to the IOTF classification) considered their children's weight as normal or lower than normal ${ }^{(13)}$. The use in the present study of reported measures to estimate the child's weight status could explain the higher misperception found among parents of children with obesity. When measured height and weight were used to 
assign a weight status (according to the WHO classification) in a sample of children aged 3-45 months, $70 \%$ of parents of children with obesity failed to recognize the excess weight situation ${ }^{(19)}$. Globally, a recent review estimated that the overall rate of parental underestimation of overweight/obesity was 67.5 (95\% CI $62.9, \quad 71.7) \%{ }^{(37)}$. Parental misperception of child's weight status seems to be more likely among younger children, especially under 6 years of age ${ }^{(13,31,34,37)}$. Carnell et al. described that only $1.9 \%$ of parents of children with overweight and 17.1\% of parents of children with obesity described their child as overweight, suggesting that parents of 3-5-year-old children show poor awareness of their child's current weight status ${ }^{(33)}$. At theses ages, excess weight could be more accepted because it is believed to be a transitory characteristic that will disappear with growth. Moreover, the prevailing health message to parents of young children is to encourage growth, and heaviness may even be viewed as an indicator of good health. Scepticism towards the identification of a child as being overweight has been justified in qualitative studies with parents because of the natural variety of body shape among children and the continuous changes that take place in growth and development during the maturation process ${ }^{(35)}$. Parents failed to categorize their children's weight according to medically defined definitions of overweight, they seemed to not understand, use or trust clinical measures, and used alternative approaches primarily reliant on extreme cases ${ }^{(33,36)}$. Parental misperception about child weight status is relevant, since there is evidence that parents who perceive their child as overweight are more likely to view their child's diet, physical activity patterns and risk of obesity as a health threat and childhood obesity as a serious problem $^{(39)}$, and parental concern about child weight is associated with specific actions to improve diet and increase physical activity ${ }^{(40)}$.

\section{Study strengths and limitations}

Among the strengths of the present study, the large size of the sample, the high participation rate and its representativeness at population level should be mentioned. It focuses on a paediatric age group that is not well studied and with specific characteristics which recommend their study separately from other ages. It also gathers information from children's caregivers other than the parents (grandparents, etc.), so data obtained are more assimilated to the real situation of data collected in paediatric revision visits. The use of both the WHO and the IOTF classifications to categorize the weight status of children facilitates comparisons with other studies. The analysis of data of children belonging to a cohort, with their correspondent follow-ups, will allow to assess changes in the same individuals and to identify related factors.
Some limitations of the study should be addressed. BMI, which was used to classify weight categories, can erroneously classify some children, especially those situated at the low 'without excess weight' level or those with BMI values close to the cut-off values of the weight categories. The analysis of reported and measured data covered all children assisted in the paediatric revision visit, regardless of their participation in the ELOIN cohort, but the parental misperception was estimated from data gathered in the questionnaires answered by parents who agreed to participate in the cohort, so it could be affected by a lower representativeness of children from families with a low educational attainment and those from families with foreign parents with language difficulties. The parental subjective perception of the child's weight was provided after the paediatric revision visit in which anthropometric measures were collected, so it could be affected by the subsequent commentaries and recommendations from the health professional. Also, the stigma linked to the word 'fat' could have conditioned the response for some parents. The cultural factors that presumably condition subjective weight appraisal may also limit the data extrapolation to other populations.

\section{Conclusions}

Parent-reported measures underestimated children's height and weight, leading to an overestimation of the BMI and of the attributed weight status. Both the individual classification of the weight status of pre-schoolers and the population estimation of overweight and obesity should be based on objective measures of weight and height. The sensitivity for identifying children with obesity using reported data was low, raising doubts regarding the accuracy of using these data for surveillance and investigation in childhood obesity. Studies with those objectives, including health surveys, should systematically incorporate the standardized collection of these measurements and stop using reported data. Parents' report of child weight status is unreliable, half of the parents of pre-schoolers with obesity failed to identify their weight status. The collection of information on this issue should avoid the use of stigmatizing language. Parental misperception of child weight status is relevant and health professionals should be aware of it. Parental awareness and acknowledgement of child weight status should be improved. Health professionals have the responsibility to adequately inform parents about the weight status of their children and about the impact of excess weight on health from an early age. Factors related with misperception and strategies of intervention should be more deeply studied, as well as its implications for weight concern and its potential effects on the later evolution of a child's weight status. 


\section{Acknowledgements}

Acknowledgements: Thanks are due to the families, children and health staff of the Madrid Primary Care Physicians Sentinel Network for their participation. Financial support: This research received no specific grant from any funding agency in the public, commercial or not-for-profit sectors. Conflict of interest: The authors have no conflicts of interest to disclose. Authorship: M.D.E.-V., I.G. and H.O.-M. designed the study. A.A.S.M., E.M.C.L. and M.T.M.S.J. participated in data collection. I.G., H.O.-M. and M.A.O.-P. supervised the analysis. M.D.E.-V. undertook the initial analysis and prepared the first draft of the manuscript. All the authors contributed to the data interpretation, the drafting process and have approved the final manuscript. Ethics of buman subject participation: This study was conducted according to the guidelines laid down in the Declaration of Helsinki and all procedures involving human subjects were approved by the ethics committee of the Hospital Ramón y Cajal de Madrid. Written informed consent was obtained from all subjects' parents.

\section{Supplementary material}

To view supplementary material for this article, please visit https://doi.org/10.1017/S1368980019003008

\section{References}

1. Dietz WH (1998) Health consequences of obesity in youth: childhood predictors of adult disease. Pediatrics 101, 518-525.

2. Freedman DS, Dietz WH, Srinivasan SR et al. (1999) The relation of overweight to cardiovascular risk factors among children and adolescents: the Bogalusa Heart Study. Pediatrics 103, 1175-1182.

3. Kelsey MM, Zaepfel A, Bjornstad P et al. (2014) Age-related consequences of childhood obesity. Gerontology $\mathbf{6 0}$, 222-228.

4. Must A \& Strauss RS (1999) Risks and consequences of childhood and adolescent obesity. Int J Obes Relat Metab Disord 23, Suppl. 2, S2-S11.

5. Branca F, Nikogosian H \& Lobstein T (editors) (2007) The Challenge of Obesity in the WHO European Region and Strategies for Response. Copenhagen: Who Regional Office for Europe.

6. Wijnhoven TM, Van Raaij JM, Spinelli A et al. (2014) WHO European childhood obesity surveillance initiative: body mass index and level of overweight among 6-9-year-old children from school year 2007/2008 to school year 2009/ 2010. BMC Public Health 14, 806.

7. Jones RE, Jewell J, Saksena R et al. (2017) Overweight and obesity in children under 5 years: surveillance opportunities and challenges for the WHO European Region. Front Public Health 5, 58.

8. Akinbami LJ \& Ogden CL (2009) Childhood overweight prevalence in the United States: the impact of parentreported height and weight. Obesity (Silver Spring) 17, $1574-1580$
9. Blumberg SJ, Foster EB, Frasier AM et al. (2012) Design and operation of the National Survey of Children's Health, 2007. Vital Health Stat 1 issue 55, 1-149.

10. Ministry of Health, Consumer Affairs and Social Welfare (2018) National health survey 2017. https://www.mscbs.gob.es/ estadEstudios/estadisticas/encuestaNacional/encuesta2017. htm (accessed June 2018).

11. Rietmeijer-Mentink M, Paulis WD, Van Middelkoop M et al. (2013) Difference between parental perception and actual weight status of children: a systematic review. Matern Child Nutr 9, 3-22.

12. Warschburger P \& Kroller K (2012) Childhood overweight and obesity: maternal perceptions of the time for engaging in child weight management. BMC Public Health 12, 295.

13. Ramiro-González MD, Sanz-Barbero B \& Royo-Bordonada MA (2017) Childhood excess weight in Spain from 2006 to 2012. Determinants and parental misperception. Rev Esp Cardiol (Engl Ed) 70, 656-663.

14. Ortíz-Marrón H, Cuadrado-Gamarra JI, Esteban-Vasallo M et al. (2016) The Longitudinal Childhood Obesity Study (ELOIN): design, participation and characteristics of the baseline sample. Rev Esp Cardiol (Engl Ed) 69, 521-523.

15. Pérez-Farinos N, Galán I, Ordobás M et al. (2009) A sampling design for a sentinel general practitioner network. Gac Sanit 23, 186-191.

16. World Health Organization (2006) WHO Child Growth Standards: Length/Height-for-Age, Weight-for-Age, Weightfor-Length, Weight-for-Height and Body Mass Index-forAge: Methods and Development. Geneva: WHO.

17. Cole TJ, Bellizzi MC, Flegal KM et al. (2000) Establishing a standard definition for child overweight and obesity worldwide: international survey. BMJ 320, 1240-1243.

18. Cole TJ \& Lobstein T (2012) Extended international (IOTF) body mass index cut-offs for thinness, overweight and obesity. Pediatr Obes 7, 284-294.

19. Patiño-Villena B, Chirlaque MD, Salmerón D et al. (2016) Validity of anthropometric measurements and weight perceptions reported by relatives of children under 4 years old. Gac Sanit 30, 300-303.

20. Rajmil L, López-Aguila S \& Mompart-Penina A (2011) Healthrelated quality of life and factors associated with overweight and obesity in the pediatric population of Catalonia, Spain. Med Clin (Barc) 137, Suppl. 2, 37-41.

21. Gordon NP \& Mellor RG (2015) Accuracy of parent-reported information for estimating prevalence of overweight and obesity in a race-ethnically diverse pediatric clinic population aged 3 to 12. BMC Pediatr 15, 5.

22. Shields M, Connor GS, Janssen I et al. (2011) Obesity estimates for children based on parent-reported versus direct measures. Health Rep 22, 47-58.

23. Weden MM, Brownell PB, Rendall MS et al. (2013) Parentreported height and weight as sources of bias in survey estimates of childhood obesity. Am J Epidemiol 178, 461-473.

24. O'Connor DP \& Gugenheim JJ (2011) Comparison of measured and parents' reported height and weight in children and adolescents. Obesity (Silver Spring) 19, 1040-1046.

25. Dubois L \& Girad M (2007) Accuracy of maternal reports of pre-schoolers' weights and heights as estimates of BMI values. Int J Epidemiol 36, 132-138.

26. Banach A, Wade TJ, Cairney J et al. (2007) Comparison of anthropometry and parent-reported height and weight among nine year olds. Can J Public Health 98, 251-253.

27. Brettschneider AK, Rosario AS \& Ellert U (2011) Validity and predictors of BMI derived from self-reported height and weight among 11- to 17-year-old German adolescents from the KiGGS study. BMC Res Notes $\mathbf{4}, 414$. 
28. Garcia-Marcos L, Valverde-Molina J, Sanchez-Solis M et al. (2006) Validity of parent-reported height and weight for defining obesity among asthmatic and nonasthmatic school children. Int Arch Allergy Immunol 139, 139-145.

29. Huybrechts I, De Bacquer D, Van Trimpont I et al. (2006) Validity of parentally reported weight and height for preschoolaged children in Belgium and its impact on classification into body mass index categories. Pediatrics 118, 2109-2118.

30. Rendall MS, Weden MM, Lau C et al. (2014) Evaluation of bias in estimates of early childhood obesity from parent-reported heights and weights. Am J Public Health 104, 1255-1262.

31. He J \& Fan X (2018) How accurate is using parent-reported height and weight for screening children and adolescents for overweight and obesity? Meta-analyses at both population and individual levels. Child Obes 14, 302-315.

32. Cattaneo A, Monasta L, Stamatakis E et al. (2010) Overweight and obesity in infants and pre-school children in the European Union: a review of existing data. Obes Rev 11, 389-398.

33. Carnell S, Edwards C, Croker H et al. (2005) Parental perceptions of overweight in 3-5 y olds. Int J Obes (Lond) 29, 353-355.

34. De Ruiter I, Olmedo-Requena R \& Jiménez-Moleón JJ (2017) Parental and child factors associated with under-estimation of children with excess weight in Spain. Matern Child Health J 21, 2052-2060.
35. Doolen J, Alpert PT \& Miller SK (2009) Parental disconnect between perceived and actual weight status of children: a metasynthesis of the current research. J Am Acad Nurse Pract 21, 160-166.

36. Jones AR, Parkinson KN, Drewett RF et al. (2011) Parental perceptions of weight status in children: the Gateshead Millennium Study. Int J Obes (Lond) $\mathbf{3 5}$, 953-962.

37. Lundahl A, Kidwell KM \& Nelson TD (2014) Parental underestimates of child weight: a meta-analysis. Pediatrics 133, E689-E703.

38. Manios Y, Moschonis G, Karatzi K et al. (2015) Large proportions of overweight and obese children, as well as their parents, underestimate children's weight status across Europe. The ENERGY (EuropeaN Energy balance Research to prevent excessive weight Gain among Youth) project. Public Health Nutr 18, 2183-2190.

39. Sylvetsky-Meni AC, Gillepsie SE, Hardy T et al. (2015) The impact of parents' categorization of their own weight and their child's weight on healthy lifestyle promoting beliefs and practices. J Obes 2015, 307381.

40. Moore LC, Harris CV \& Bradlyn AS (2012) Exploring the relationship between parental concern and the management of childhood obesity. Matern Child Health J 16, 902-908. 